\title{
The Propose of an Instructional Model Based on STEM Education Approach for Enhancing the Information and Communication Technology Skills for Elementary Students in Thailand
}

\author{
Sukruetai Changpetch ${ }^{1} \&$ Thapanee Seechaliao ${ }^{1}$ \\ ${ }^{1}$ Educational technology and communications department, Faculty of Education, Mahasarakham University, \\ Thailand \\ Correspondence: Sukruetai Changpetch, Educational technology and communications department, Faculty of \\ Education, Mahasarakham University, Thailand.
}

Received: August 25, 2019

doi:10.5539/ies.v13n1p69
Accepted: October 7, $2019 \quad$ Online Published: December 30, 2019

URL: https://doi.org/10.5539/ies.v13n1p69

\begin{abstract}
The purpose of this research is to propose an instructional model based on Science, Technology, Engineering, and Math (STEM) Education approach for enhancing the information and communication technology skills for elementary students in Thailand. The study was conducted by research and development design and divided into two phases: Phase I is to create a tentative model that was synthesized using the relevant documents and researches concerning the elements and steps of the model. The data was collected through interviewing eight teachers who are experts in STEM education and twenty-four students who were instructed by STEM approach. Phase II consists of proposing a tentative model to eleven experts, evaluating the model, and acquiring an approval of the model by five professionals. The findings of the research are as follows: 1) This model consists of five main elements - principles, purpose, content, teaching and learning process and measurement and evaluation of ICT skills. There are six steps from the engineering design process consisting of problem identification, related information search, solution design, planning and development, testing evaluation, and design improvement and presentation. 2) The eleven experts evaluated the tentative model as appropriate at a high level. The five professionals approved this model as appropriate at a high level.
\end{abstract}

Keywords: instructional model, STEM education approach, information, communication technology, skills, elementary students

\section{Introduction}

Educational provision of Thailand intends to develop skills and competencies for the 21st-century world for learners. The purpose of development is to develop learners to be citizens with intelligence, good quality of life and have the ability to compete on a global stage with five skills including communication ability, thinking ability, ability to solve problems, ability to use life skills, and ability to use technology (Bureau of Educational Testing [BET], 2012) which are in line with the concepts for learning in the 21st century. This concept includes both core subjects and three skills - learning and information skills, information, media and technology skills, and life and career skills. The emphasis of the information, technology and communication skills includes the following five essential elements: accessibility skills, management skills, integration skills, assessment skills, and creative skills. Students must use technology as a learning tool in accordance with the Thailand Information Technology and Communications Policy 2011-2020 (Ministry of Information and Communication Technology, 2011), which focuses on economic and social activities based on knowledge and wisdom.

Bureau of academic affairs and educational standards office of the basic education commission (2016) announced the thirteen indicators to assess the computer and technology courses for sixth-grade elementary students in Thailand which also included the assessment of the key competencies. Additionally, the key competencies are systematic measurement and evaluation of the ability to use technology. There are two important indicators - selecting and using technology for self and social development and having technological process skills (BET, 2012).

A STEM education is an approach to learning management for students to learn and be able to integrate scientific knowledge, technology, mathematics, and engineering processes. The development of new processes or products 
according to the development of 21 st-century skills could connect and solve real-life problems. STEM education is managed through activities or projects. The learners actively took part in the learning process engaging in activities to develop knowledge with their own understanding, identifying problems, practicing analysis, designing methods or problem-solving processes, planning and implementing solutions, testing, checking, improving solutions or products and offering solutions to solve problems (Cosentino, 2013).

The Standards for Technological Literacy identify content standards for grades K-12 that provide students' opportunities to think critically about technology beyond technology as an object and prepare students to become technologically literate. STEM educators should provide students opportunities to think through technology as a vehicle for change with both positive and negative impacts on culture, society, politics, economy, and the environment (International Technology Education Association, 2003). The relevant documents about technology supporting the STEM learning management found that smartphones and social media are the sources of entertainment and communication for many students, both inside and outside of school, for example, 1) Facebook 2) Twitter 3) YouTube 4) SMS 5) Line 6) WhatsApp (Palekahelu, Hunt, Thrupp, \& Relmasira, 2016).

Instructional design is the systematic approach to organize appropriate teaching situations that can achieve learning goals, creation of learning experiences, application of knowledge and skills. The previous relevant documents and researcher studies found five critically important steps from implementing the instruction model based on constructivism learning theory and STEM Education approach to enhance analytical thinking and scientific literacy for mathayomsuksa 1 students. The results of the evaluation by the experts showed that the model has been appropriately improved at a high level and students with scientific literacy have the performance scores higher than before attending the class (Jitaree, Uaiy, \& Keawurai, 2017).

Therefore, STEM education is an approach to enhance ICT skills. This research was to create a tentative model and propose the instructional model based on STEM Education approach for enhancing the ICT skills for elementary students in Thailand including 1) information access 2) data collection 3) information presentation 4) usage of application software and 5) product creation which expressed the importance of implementing the teaching and learning approach to enhance ICT skills for elementary students. This instructional model could help learners achieve more as expected in the 21 st Century.

\section{Literature Review}

The literature review consists of the following concepts and theories.

\subsection{The Instructional Model}

The instructional model is a systematic approach to organize appropriate teaching situations that can achieve learning goals. The basis of references is philosophy, theories, principles, concepts or beliefs which consists of important steps or procedures in teaching and learning. Specific objectives are statements that describe the model that include teaching methods and teaching techniques to help learners (Eggen \& Kauchak, 2006; Joyce, 2009; Khammanee, 2017).

\subsection{The STEM Education}

Nowadays, there are many strategies for teaching and learning. STEM education is an interdisciplinary approach to learning where rigorous academic concepts are coupled with real-world lessons as students apply science, technology, engineering, and mathematics in contexts that make connections between school, community, work, and the global enterprise enabling the development of STEM literacy and the ability to compete in the new economy (Tsupros, Kohler, \& Hallinen, 2009). STEM Education focused on integrating science, mathematics, and technology and using engineering design processes. The engineering design process consists of six elements-1) problem identification 2) related information search 3) solution design 4) planning and development 5) testing evaluation and design improvement and 6) presentation (Cosentino, 2013).

\subsection{Technology Supporting the STEM Education}

Learning beyond the traditional classroom is also driven by a large amount of free, open-source software and hardware available which generate active, vibrant social communities. The social nature of the internet has created an environment of learning that encourages users to use, create, invent and improve upon what is already available. Participation in communities such as Facebook and Line empowers students to learn and develop confidence in their skills, through relevant, real-world projects. Social sites are used to share new discoveries and new skills around open-source software and hardware used in STEM education. Appropriate support technology is used to develop full-scale teaching. Smartphones and social media are the source of entertainment and communication for many students, both inside and outside of school (Palekahelu et al., 2016). The progress of technology especially the support of learning management by using it as a tool to help reflect learning outcomes 
and evaluation of learning management in a diverse classroom, organize teaching that can incorporate technology to enhance learning in which technology is benefits to both teachers and students.

\subsection{Information and Communication Technology Skills for Elementary School Students}

Knowledge of ICT and related skills shows an important competency in present educational activities. The indicators of skill for elementary students presented that were 1) selective and usage of technology for self and social development, and 2) acquire technological process skills due to the widespread use of information and communication technology especially at the elementary level. According to two important indicators in the assessment of Information and communication technology skills for elementary school students found five key competencies including; 1) information access 2) data collection 3) information presentation 4) usage of application software and 5) product creation (Srisakda, Sujiva, \& Pasiphol, 2016).

\subsection{Measurement and Evaluation of Information and Communication Technology Skills}

The indicators of information and communication technology for elementary schools in Thailand have been created the parallel requirements to measure the quantity and quality of information and communication technology. Measurement and evaluation of information and communication technology skills found that two methods can be used. These include authentic assessment and performance assessment (The Bureau of academic affairs and educational standards office of the basic education commission, 2016).

\section{Method}

This research proceeds in two phases.

Phase I: The main purpose in phase I, that was to create a tentative model following these three steps 1) conceptual study 2) explore elementary schools using the STEM education approach 3) study the opinions of teachers and students by interview. Research instruments: 1) synthetic conceptual study form 2) teachers' interview form and 3) students' interview form. The samples were eight teachers and twenty-four sixth grade students in the STEM region, where was in the upper northeast region with a center located in Khon Kaen, Thailand. Questionnaires and semi-structured interviews were collected. The data were analyzed by descriptive data and summarized interpretation.

Phase II: The main purpose in phase II was to propose a tentative model to eleven experts and evaluate a tentative model, and then make an approval model by five professionals. Research instruments: 1) Tentative model containing a lesson plan based on STEM Education approach for enhancing the ICT skills 2) evaluate form for experts 3) evaluate form for professionals. Data analysis was the evaluation in the rating scale form scored by using the arithmetic mean and standard deviation.

\section{Results}

Phase I: The result of the study was a tentative model of the instructional model based on STEM education approach for enhancing the ICT skills for elementary students in Thailand consist of four main elements: 1) principles, 2) purpose, 3) teaching and learning process and 4) measurement and evaluation of ICT skills. There are six steps from the engineering design process consists of 1) problem identification, 2) related information search, 3) solution design, 4) planning and development, 5) testing evaluation and design improvement and 6) presentation. Each step has been integrated technology to support learning activities.

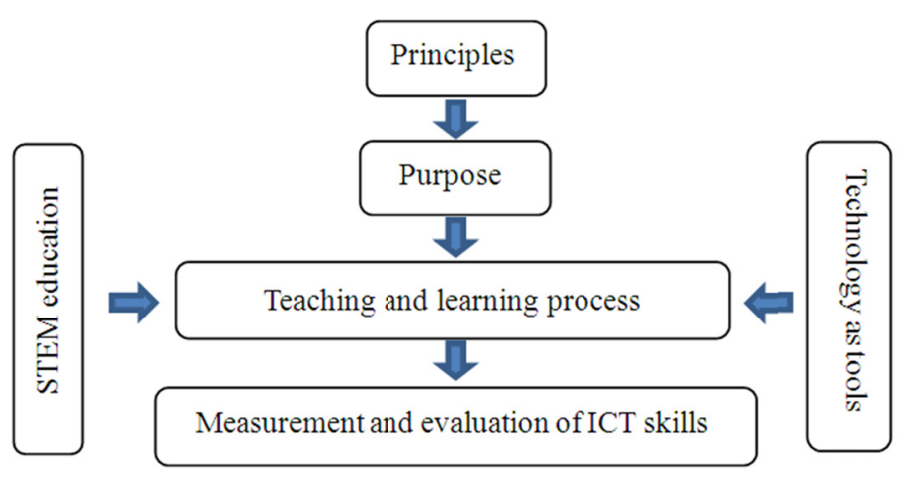

Figure 1. Structural of a tentative model 
Phase II: The results of the model evaluation by eleven experts found that the model was appropriate at a high level and the evaluation quality of the model by five professionals found that the model was appropriate at a high level.

Table 1. The evaluated a tentative model of the experts

\begin{tabular}{lccc}
\hline \multirow{2}{*}{ Elements of the instructional model } & \multicolumn{3}{c}{ Results } \\
\cline { 2 - 4 } & $\mathrm{x}$ & S.D. & Level of appropriateness \\
\hline principles and purpose of the model & 4.40 & 0.52 & High \\
the teaching and learning process of the model & 4.40 & 0.68 & High \\
measurement and evaluation of ICT skills of the model & 4.47 & 0.65 & High \\
the appropriateness of the overall process & 4.51 & 0.82 & Most high \\
Overall average & 4.44 & 0.67 & High \\
\hline
\end{tabular}

Table 1 presents the evaluated a tentative model of experts. The overall average arithmetic mean was 4.44 and the standard deviation was 0.67 , means that this model has an overall average at a high level.

Table 2. The assessment and qualified models of professionals

\begin{tabular}{lccc}
\hline \multirow{2}{*}{ Elements of the instructional model } & \multicolumn{3}{c}{ Results } \\
\cline { 2 - 4 } & $\mathrm{x}$ & S.D. & Level of appropriateness \\
\hline principles of the model & 3.60 & 1.67 & High \\
the purpose of the model & 4.00 & 0.71 & High \\
the teaching and learning process of the model & 4.23 & 0.83 & High \\
measurement and evaluation of ICT skills of the model & 4.33 & 0.48 & High \\
Overall average & 4.04 & 0.92 & High \\
\hline
\end{tabular}

Table 2 presents the result of the evaluation and certifying the quality of the model by professionals found that the model was appropriate at a high level.

The details of this model are as follows:

Principles: The instructional model based on STEM Education approach for enhancing the ICT skills for elementary students in Thailand based on the following principles: 1)Manage class focus on integration allowing students to see the relationship and consistency of science, mathematics, and technology using engineering design processes allowing the learners to process the knowledge gained from searching and collecting data, assessing, making choices and use of knowledge to design solutions to solve problems or create products, 2)The learner actively took part in the learning process engaging in activities to develop knowledge with their own understanding, identifying problems, practicing analysis, designing methods or problem-solving processes, planning and implementing solutions, testing, checking, improving solutions or products and offering solutions to solve problems, 3)Learners cooperate with the group work process expressing ideas, brainstorming, and creating a product from knowledge, experience, activities and being able to integrate knowledge to apply in daily life, 4)Learners developed their skills in using ICT which is the key competency of the learner, i.e. information access, data collection, information presentation, usage of application software, and product creation.

Purpose: This model was to develop skills in using ICT for elementary school students.

Teaching and learning process: Practice in teaching and learning with STEM education concepts processed content with the teaching of engineering design which consists of six steps including 1) problem identification 2) related information search 3)solution design 4) planning and development 5) testing evaluation and design improvement and 6) presentation. The details of teaching and learning process based on the engineering design process and appropriate technology as tools consist of six elements which describe the following details; 1)problem identification that learners could stimulate learning with problem situations and brainstorm to find a solution to solve problems, 2) related information search that learners could collect and search for information for support ideas, 3) solution design that learners could apply data to design methods, define elements and problem-solving projects, 4) planning and development that learners could develop a sub-process prototype for work targeting and set timing, 5) testing evaluation and design improvement that learners could test the performance evaluation according to the actual condition. If found defects, improve the solution and 6) the presentation that learners could demonstrate with appropriate technology. 


\section{Principles}

The instructional model based on STEM education approach for enhancing the ICT skills for elementary students in Thailand based on the following principles:

1. Manage class focus on integration allowing students to see the relationship and consistency of science, mathematics, and technology using engmeering design processes allowing the le amers to process the knowledge gaimed from searching and collecting data, assessing, making choices and use of knowledge to design solutions to solve problems or create products.

2.The leamer actively took part in the leaming process engaging in activities to develop knowledge with their own understanding, identifying problems, practicing analysis, designing methods or problem-solving processes, planning and implementing solutions, testing, checking, improving solutions or products and offering solutions to solve problems.

3.Leamers cooperate with the group work process expressing ideas, brainstorming, and creating a product from knowledge, experience, activities and being able to integrate lnowledge to apply in daily life.

4.Leamers developed their skills in using ICT which is the key competency of the leamer, i.e. information access, data collection, information presentation, usage of application software, and product creation.

\section{Purpose}

This model was to develop skills in using ICT for elementary school students.

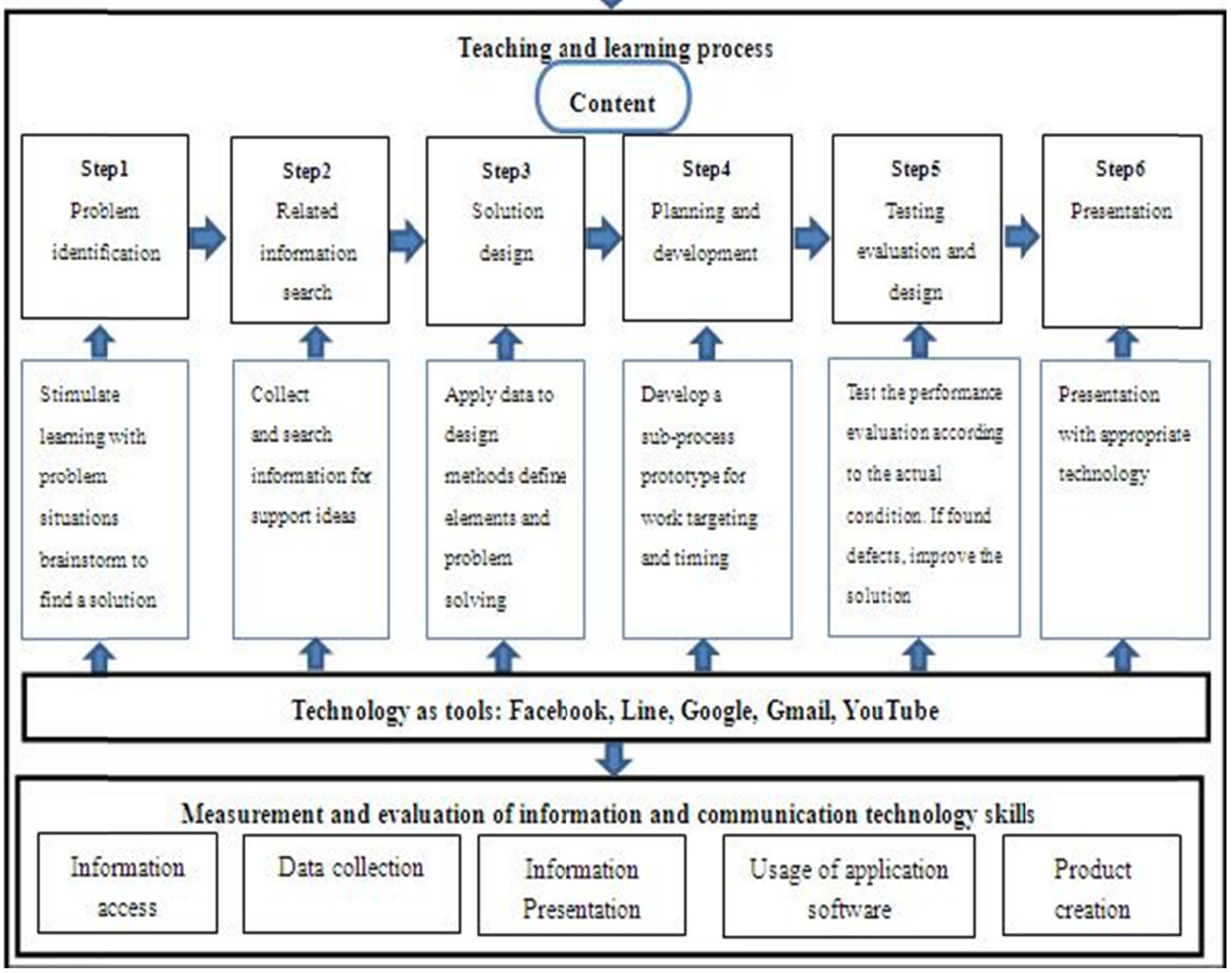

Figure 2. Structural of model 


\section{Discussion}

Elements of the instructional model according to the STEM approach to developing skills in using information and communication technology for elementary school students are as follows; 1)principles 2) purpose 3) content 4) teaching and learning process and 5) measurement and evaluation of information and communication technology skills which has important features in the teaching and learning process, using engineering design processes as the basis of operations in accordance with Keeves (1988), Joyce (2009), Branch (2010), and Khammanee (2017). This model was be integrated the engineering design process that consists of problem identification, related information search, solution design, planning and development, testing evaluation and design improvement and presentation. It could encourage elementary school students and develop skills in using information and communication technology perfectly.

This model was qualified by professionals. Overall average presented arithmetic mean was 4.05 and the standard deviation was 0.92 , which means that the model was approved at a high level. According to this systematical model could develop learner's skills in using ICT. Elementary school students could use of knowledge to design solutions, solve problems or create their products by using STEM Educational approach. This model was similar to Jitaree et al. (2017). They developed the instruction model based on constructivism learning theory and STEM Education approach to enhance analytical thinking and scientific literacy for mathayomsuksa 1 student which has developed the model systematically.

\section{References}

Branch, R. M. (2010). Design. Instructional Design: The ADDIE Approach (pp. 58-81). https://doi.org/10.1007/978-0-387-09506-6_3

Cosentino, T. (2013). STEM Lesson Essentials. Science and Children, 50(9), 75.

Eggen, P. D., \& Kauchak, D. P. (2006). Strategies and Models for Teachers Teaching Content and Thinking Skills (5th ed.). Pearson Education Inc.

Jitaree, R., Uaiy, V., \& Keawurai, W. (2017). The development of instruction model based on constructivism learning theory and STEM Education approach to enhance analytical thinking and scientific literacy for mathayomsuksa 1 student. Journal of Education Naresuan University, 19(2), 202-213.

Joyce, B. R. (2009). Models of teaching (8th ed.). Boston, Ma: Pearson Education, Inc.

Keeves, J. P. (1988). Educational research, Methodology, and Measurement: An International Handbook. New York: Pergamon.

Khammanee, T. (2017). Model of alternative teaching and learning (21st ed.). Bangkok: Chulalongkorn university press.

Ministry of Information and Communication Technology. (2011). Executive Summary of Thailand Information and Communication Technology Policy Framework (2011-2020). Bangkok.

Palekahelu, D. T., Hunt, J., Thrupp, R.-M., \& Relmasira, S. (2016). The Use of Smartphones and Social Media in Schools of Kota Salatiga, Central Java. International Conference on Information, Communication Technologies in Education (pp. 102-111). Retrieved from http://www.icicte.org/Papers_ICICTE2016/3.3016_Huntedit(2).pdf

Pongsupan, P., Sinlarat, P., \& Kiewkor, S. (2019). The Development of a STEM-Enriched Curriculum to enhance the Creative Thinking and Productive Thinking Skills of Prathomsuksa 4 Students. Journal of Education Studies, 47(1), 219-239.

Srisakda, B., Sujiva, S., \& Pasiphol, S. (2016). Development of Indicators of Learner's Key Competencies Based on the Basic Education Core Curriculum. Procedia-Social and Behavioral Sciences, 217, 239-248. https://doi.org/10.1016/j.sbspro.2016.02.075

STEM Education Thailand. (2014). STEM Education network. Retrieved from http://www.stemedthailand.org/

The Bureau of academic affairs and educational standards office of the basic education commission. (2016). Key indicators and core learning content must be known and should be known. Bangkok.

The Bureau of Educational Testing. (2012). Handbook of a Competency Appraisal for Basic Education Students based on the Basic Education Core Curriculum B.E.2551 (A.D. 2008) (Office of the Basic Education Commission, Ed.). Bangkok: Buddhapress.

The Ministry of Education in Thailand. (2008). The Basic Education Core Curriculum B.E. 2551 (A.D. 2008) 
(The Ministry of Education, Ed.). Retrieved from http://www.act.ac.th/document/1741.pdf

Tsupros, N., Kohler, R., \& Hallinen, J. (2009). STEM education: A project to identify the missing components. Intermediate Unit 1: Center for STEM Education and Leonard Gelfand Center for Service Learning and Outreach, Carnegie Mellon University, Pennsylvania.

\section{Copyrights}

Copyright for this article is retained by the author(s), with first publication rights granted to the journal.

This is an open-access article distributed under the terms and conditions of the Creative Commons Attribution license (http://creativecommons.org/licenses/by/4.0/). 